\title{
LOS ARCHIVOS SEÑORIALES CASTELLANOS A FINALES DE LA EDAD MEDIA*
}

\author{
CASTILIAN SEIGNEURIAL ARCHIVES \\ AT THE END OF THE MIDDLE AGES
}

\author{
EFRÉN DE LA PEÑA BARROSO \\ Cuerpo Facultativo de Archiveros, Bibliotecarios y Arqueólogos \\ http://orcid.org/0000-0003-0686-366X
}

\begin{abstract}
Resumen: La organización de los archivos señoriales castellanos se configuró de manera definitiva durante las últimas décadas de la Edad Media. Los señores, conscientes del valor de su documentación, desplegaron archivos en cada una de sus fortalezas y encargaron su custodia a sus alcaides. Los documentos, conservados normalmente en arcas de madera, eran referenciados en precisos inventarios que facilitaban su localización. De este modo, los archivos señoriales cumplieron el propósito para el que fueron creados, sentando las bases de las prácticas archivísticas que se desarrollaron en los siglos siguientes.
\end{abstract}

Palabras clave: documentos; archivos; archivística; señoríos; Castilla; Edad Media.

\begin{abstract}
The organization of the documents in the archives of Castilian lords was finally achieved during the last decades of the Middle Ages. Aware of the value of their documents, noblemen established their archives in each of their fortresses, and entrusted their governors with guarding them. The documents were usually kept in wooden chests, and they were referenced in precise inventories with the aim of making them easy to locate. In this way, the lords' archives fulfilled the purpose for which they were created and laid the foundations for the archival practices that were developed in the following centuries.
\end{abstract}

Keywords: documents; archives; archival science; domains; Castile; Middle Ages.

* El autor fue Jefe de la Sección de Organización de Fondos y Normalización del Archivo Histórico de la Nobleza desde octubre de 2008 hasta finales de abril de 2014. Deseo expresar mi agradecimiento a Miguel F. Gómez Vozmediano, compañero y amigo en el mencionado archivo, y a Juan J. Larios de la Rosa, anterior archivero del Archivo General de la Casa Ducal de Medinaceli, por los comentarios y sugerencias que me hicieron a lo largo de la redacción de este trabajo. 


\section{SUMARIO}

1. Introducción.- 2. Organización y estructura de los archivos señoriales.- 3. Instalación y conservación de la documentación señorial.- 3.1. Contenedores de archivo.3.2. Agrupaciones documentales.- 3.3. Otras formas de instalación.- 3.4. Conservación de la documentación señorial.- 3.5. Copias y traslados.- 4. Organización y descripción de la documentación señorial.- 4.1. Inventarios.- 4.2. Cartularios y registros.- 5. Conclusiones.- 6. Bibliografía citada.

\section{INTRODUCCIÓN ${ }^{1}$}

El proceso de organización de los archivos señoriales castellanos se desarrolló y afianzó durante los últimos siglos de la Edad Media. En ese largo período la función jurisdiccional de los señores se fue extendiendo y consolidando a través de las mercedes y privilegios otorgados por los distintos monarcas en agradecimiento a los servicios que éstos les habían prestado. Este hecho provocó que un buen número de nobles y otros señores, fundamentalmente aquellos de mayor importancia, se rodearan de oficiales que se encargaron de redactar y expedir los documentos necesarios para la gestión y el gobierno efectivo de unos dominios jurisdiccionales en constante expansión ${ }^{2}$.

Las crecientes funciones de estos oficiales motivaron que, paralelamente, se hiciese necesario conservar y organizar la documentación producida y también la que era recibida de otras instituciones. El conjunto de esa documentación estaba formado por los títulos de los derechos jurisdiccionales de los señores, los informes y cuentas sobre la administración de su patrimonio y todos aquellos testimonios de naturaleza jurídico-económica que en algún momento pudiesen servir para defender sus intereses ${ }^{3}$. De este modo el patrimonio documental señorial, acrecentado por las herencias, la adquisición de nuevos derechos o los enlaces matrimoniales, se reveló como una fuente de derechos de primer orden

${ }^{1}$ Abreviaturas utilizadas: AGS = Archivo General de Simancas; AHNob = Archivo Histórico de la Nobleza; $\mathrm{C}=$ caja; $\mathrm{CP}=$ carpeta; $\mathrm{D}=$ documento; $\mathrm{f}=$ folio; $\mathrm{ff}=$ folios; leg = legajo; $\mathrm{RGS}$ $=$ Registro General del Sello.

${ }^{2}$ No hay estudios definitivos sobre las cancillerías señoriales castellanas en la Edad Media, sino tan sólo alguna aproximación. Véase Sanz 1999, p. 330; Pardo 1994-1995. Sería interesante abrir un debate para determinar hasta qué punto puede hablarse de cancillerías señoriales medievales en la Corona de Castilla. Los testimonios documentales manejados indican que los oficiales señoriales siguieron determinadas prácticas cancillerescas, pero no sugieren ni siquiera vagamente que existiese una cancillería señorial con una estructura orgánica definida al estilo de la cancillería real.

${ }^{3}$ Contel 1994, p. 398. 
cuya conservación y organización fue primordial para poder ejercerlos a lo largo del tiempo ${ }^{4}$.

Los archivos señoriales bajomedievales, al igual que ocurrió con los archivos de los monarcas, cabildos catedralicios, concejos urbanos o universidades, fueron configurándose como depósitos de documentación más o menos organizados sobre los que se desarrollaron un conjunto de prácticas archivísticas efectivas y flexibles que evolucionaron según las necesidades administrativas de cada momento.

Sin embargo, ese incipiente desarrollo técnico no condicionó en modo alguno la organización y conservación de la documentación señorial. Muy al contrario, esas rudimentarias prácticas archivísticas seguidas en los archivos señoriales castellanos de finales de la Edad Media fueron tan efectivas que sentaron las bases para la configuración de la disciplina durante los siglos siguientes. Los ejemplos que veremos a continuación son el mejor testimonio de la utilidad, evolución y vigencia actual de algunas de ellas.

\section{ORGANIZACIÓN Y ESTRUCTURA DE LOS ARCHIVOS SEÑORIALES}

La función principal del archivo señorial era la de custodiar los documentos del señor, sobre todo aquellos que servían como defensa de sus intereses jurídicos y económicos. No obstante, es necesario matizar que en la Baja Edad Media no existió el archivo señorial como espacio físico determinado. De hecho, antes del siglo XIV era común que la documentación señorial ni siquiera se conservase en las fortalezas señoriales, sino que se guardase en centros monásticos o catedralicios mezclada con la documentación propia de esas instituciones ${ }^{5}$, sobre todo si estas habían adquirido total o parcialmente un determinado dominio territorial ${ }^{6}$. La utilización de monasterios e iglesias como depósitos de documentación señorial era aún más evidente cuando esos centros se encontraban insertos dentro del régimen de propios tan frecuente en los siglos plenomedievales ${ }^{7}$.

\footnotetext{
${ }^{4}$ Miguel Calleja ha apuntado con acierto que el documento escrito "se convierte en un importante elemento articulador de las relaciones sociales, un campo de batalla en sí mismo, y un elemento pacificador, que cierra los conflictos", todo ello debido a su valor probatorio. Véase Calleja 2014, p. 210.

${ }^{5}$ En el Monasterio de Santa María de Otero de las Dueñas (León) se ha conservado un pergamino del año 976 cuyo contenido hace referencia a la voluntad de una familia de la nobleza menor de la zona para que se custodiasen ciertos documentos que les concernían en el archivo de ese monasterio. Citado en ibidem, p. 211.

${ }^{6}$ Beceiro, Córdoba 1990, p. 14. Véase también Cavero 2004, pp. 80-81.

${ }^{7}$ Calleja 2002,p. 17.
} 
Pero desde el siglo XIV los señores castellanos, conscientes del valor de su documentación y de la utilización cada vez más frecuente de sus títulos jurídicos frente a particulares y otras instituciones, evidenciaron su voluntad por recuperar y concentrar su patrimonio documental en sus propias fortalezas y residencias para que estuviese al servicio de sus oficiales ${ }^{8}$. Los condes de Haro, por ejemplo, conservaban sus escrituras de la Cámara (los títulos y derechos del señorío) en diferentes emplazamientos fortificados propiedad de la familia atendiendo a la relación que guardaba la documentación con esos estados. De este modo, Pedro Fernández de Velasco, conde de Haro y camarero mayor de Juan II de Castilla, ordenó en 1428 a Pedro López de Bocos, su contador, que sacase del alcázar (sin especificar de cuál) ciertas escrituras en los siguientes términos:

Pero Lopes: bed esta çédula que Garçía Sanches me enbió, et yd luego al alcáçar, pues me enbió las llaves, e sacad la escriptura que en ella dise, ca por esta mi carta mando a la muger del alcayde que vos la dé 9 .

El mismo conde ordenó en 1432 a Diego González de Rosales, alcaide del alcázar de Medina de Pomar, que entregase a Sancho Sánchez de Burga sesenta e çinco cartas e recabdos de conpras que estaban en esa fortaleza y que tocan a la casa de Santa María, porque dis que son neçesarias para algunas $\cos { }^{10}{ }^{10}$. Dos años después, en 1434, el conde también ordenó a Ferrán Sánchez de Alvarado, otro de sus oficiales y su alcaide en la fortaleza de Briviesca, que entregase a su hermano Fernando de Velasco ciertos documentos que vos tenedes en vuestro poder en el dicho alcáçar ${ }^{11}$. También se conserva una carta de 1451 por la que el conde mandó a Juan de Rojas, otro de sus alcaides, que entregase a fray Martín ciertos documentos que habían de trasladarse y permanecer en el mi alcáçar de la mi villa de Briviesca ${ }^{12}$. Por último, en 1461 se preparó un extenso inventario de las escrituras que Diego González de Rosales, alcaide que fue del alcázar de Medina de Pomar, conservaba en dicha fortaleza y que debía entregar al nuevo alcaide Ferrán Sánchez de Alvarado por orden del conde de Haro:

para que las vos toviésedes como las él tenía en guarda e en depósito en el dicho alcáçar, (...) [y] que las dedes e entreguedes luego a

\footnotetext{
${ }^{8}$ Véanse las notas expuestas por Gómez 2007, p. 133, pp. 137-138.

${ }^{9}$ AHNob, FRIAS, C.597/9. Fechado el 18 de mayo de 1428 .

${ }^{10}$ AHNob, FRÍAS, C.253/1. Fechado el 6 de julio de 1432.

${ }^{11}$ AHNob, FRIAS, C.364/3. Fechado el 9 de noviembre de 1434.

${ }^{12}$ AHNob, FRÍAS, C.597/48. Fechado el 25 de febrero de 1451.
} 
Sancho Ferrandes de Angulo, vesino de la dicha villa de Medina, fijo de Pero Ferrandes de Angulo, para que las tenga en guarda e depósito en la dicha alcáçar para faser de ella lo que yo mandare ${ }^{13}$.

Todos estos testimonios demuestran de manera evidente la dispersión intencionada de la documentación del conde de Haro entre sus distintas fortalezas. Es muy llamativo que fuesen los alcaides de las fortalezas los que, al menos hasta mediados del siglo XV, tuvieran el control de la documentación que se conservaba en ellas ${ }^{14}$. Seguramente en estas tareas estuviesen auxiliados por los escribanos señoriales de los respectivos lugares, y entre ambas figuras debió existir una estrecha vinculación que aún no ha sido estudiada.

Otra interesante circunstancia que se percibe a través del análisis de los inventarios medievales es que la documentación económica y administrativa no se conservaba en el mismo lugar que la documentación de la Cámara ${ }^{15}$. De hecho, la documentación de carácter económico, financiero y contable, al ser tramitada por los contadores o tesoreros, se guardaba en otras estancias de la fortaleza o incluso en las casas particulares del oficial encargado de la contabilidad señorial ${ }^{16}$. Así se desprende de la provisión enviada por el duque de Béjar a su primo Fernando de Sotomayor, según la cual le pedía:

que entréis en la contaduría [de la fortaleza de Belalcázar], y todos los libros que en ella ay y fuera della (...) los deis y entreguéis a Christóval de Alderete para que los tenga en tanto quanto sea mi voluntad, porque estos son míos y otro no tiene que ver en ellos ${ }^{17}$.

En ese inventario se recogen exclusivamente libros de cuentas, y entre ellos se hace mención a algunos que se conservaban en lugar distinto al de la documentación de la Cámara:

${ }^{13}$ AHNob, FRÍAS, C.253/2, f. 13v. El inventario original se realizó el 3 de agosto de 1461 , pero lo que se conserva es una copia simple fechada el 25 de mayo de 1464 . Sabemos que la mayoría de esas escrituras, si no todas, se conservaban en "çinco cofres, los tres del primero terno y los dos del postrero terno", según declaró el alcaide Juan Sánchez de Alvarado cuando se hizo cargo de ellos el 12 de noviembre de 1551. En AHNob, FRÍAS, C.253/3.

${ }^{14} \mathrm{La}$ importancia de la figura del alcaide en la estructura organizativa señorial está perfectamente explicada en Beceiro 1998, pp. 237-238.

${ }^{15}$ La documentación económica tenía además una tipología documental específica. Véase Romero 1998.

${ }^{16}$ El carácter patrimonial de estos libros se refleja en testimonios como el de "un libro de las cuentas de las rentas de la villa de Béjar e su Tierra, dende que sus señorías heredaron fasta ora, que es del tesorero Françisco Ramírez". En AHNob, OSUNA, C.221, D.58, f. 5r. Fechado en 1544 .

${ }^{17}$ Ibidem, f. 4r. Los poderes centrales y territoriales también tomaron medidas para recuperar la documentación generada por escribanos, secretarios y otros funcionarios que quedaba en sus domicilios cuando fallecían o cesaban en su oficio. Véase Navarro 2003, pp. 116-117. 
un libro antiguo del tiempo del conde de Plazencia que se començó [en el] año de mill e quatroçientos e çinquenta e siete; y a un libro viejo del estado de Çúñiga del año de [mil cuatrocientos] çinquenta e quatro e çinquenta e çinco ${ }^{18}$.

En otros inventarios consultados, como el de las escrituras conservadas en el alcázar de Medina de $\operatorname{Pomar}^{19}$ o el de las que se custodiaban en la fortaleza de Tordehumos ${ }^{20}$, tampoco se menciona documentación económica o administrativa alguna, lo que vendría a confirmar que la documentación de la Contaduría no se guardaba junto a la de la Cámara y que, además, era gestionada de forma independiente ${ }^{21}$.

La dispersión por Estados de la documentación señorial castellana, unida a la diferenciación entre los depósitos documentales de la Cámara y de la Contaduría, han llevado a algún autor a plantearse que a finales de la Edad Media pudo existir una primitiva red de archivos señoriales confiados a los distintos servidores de la Casa ${ }^{22}$. Esta separación de los depósitos de documentación se mantuvo durante las primeras décadas del siglo XVI, y tanto la secretaría particular como la contaduría mayor de la Casa y las administraciones de los distintos estados dispusieron de archivos de oficina para los asuntos que se encontraban en tramitación. Sin embargo, desde mediados de ese mismo siglo la mayoría de los señores determinaron que la documentación ya tramitada en las oficinas de origen se remitiese paulatinamente al archivo general de la $\mathrm{Casa}^{23}$.

\section{INSTALACIÓN Y CONSERVACIÓN DE LA DOCUMENTACIÓN SEÑORIAL}

En ninguno de los testimonios conservados se menciona que en las residencias señoriales hubiese estancias de archivo específicas para guardar la documentación de la Cámara. Por este motivo fue necesaria la utilización de

\footnotetext{
${ }^{18}$ AHNob, OSUNA, C.221, D.58, ff. 7r-7v.

${ }^{19}$ AHNob, FRÍAS, C.253/2.

${ }^{20}$ AHNob, OSUNA, C.1829, olim leg. 1829-11, sin foliar. Fechado en la década de 1480.

${ }^{21}$ Los libros de contaduría, por ejemplo, debían ser entregados al tesorero que sucedía en el cargo si así lo disponía el titular de la documentación: "Todos los quales dichos libros, e cada uno dellos, y escripturas que de suso se faze minçión se dieron y entregaron por el dicho señor don Fernando de Sotomayor, en complimiento de la provisión de su señoría, al dicho Christóval de Alderete, cada un libro y escriptura por sí. Y él los resçibió e pasó a su poder bien e realmente e con efecto de verdad para los tener en nonbre de su señoría de la dicha señora duquesa, mi señora, e como libros suyos e de sus estados fasta tanque que su señoría lotra/ cosa mande". En AHNob, OSUNA, C.221, D.58, f. 9v.

${ }^{22}$ Gómez 2001, p. 96; en prensa, p. 25. Agradezco al autor que me haya facilitado una copia del manuscrito.

${ }^{23}$ Lafuente 2010, p. 46.
} 
diferentes contenedores portátiles como arcas, cofres o $\operatorname{arcones}^{24}$, que solían ubicarse cerca de las estancias más íntimas y privadas del señor ${ }^{25}$. La documentación señorial se mezclaba en estos contenedores con tejidos de buena factura, joyas y todo tipo de amuletos ${ }^{26}$.

\subsection{Contenedores de archivo}

Las arcas son los muebles portátiles con funciones de archivo que más veces aparecen en la documentación. La rudimentaria organización administrativa de la mayoría de los señoríos castellanos y la todavía escasa documentación producida y recibida por los mismos a finales de la Edad Media hicieron que unas pocas arcas fuesen suficientes para conservar todos los documentos de un mismo estado señorial, sobre todo en el caso de los señoríos más pequeños. Por ejemplo, en un inventario de los bienes muebles que había en el castillo de Tordehumos fechado en 1456 se dice que había un envoltorio de escrituras en una arca cobierta de verde viejo ${ }^{27}$; y también ciertas escripturas que se pusieron en un cofre pequeño que estava dentro de otro ${ }^{28}$, quizá fabricado en madera de pino, ya que se citan otros cofres y arcas de esta madera. En otro inventario de escrituras de la misma fortaleza confeccionado unas décadas más tarde todavía se mencionaba cierta documentación que tiene su señoría de mi señora doña Mencía de la Vega en un cofre pequeño barreado ${ }^{29}$.

Estas arcas solían estar dotadas de varias cerraduras cuyas llaves estaban en poder de los oficiales señoriales en quien más se confiaba, como ocurría en el caso de los alcaides. En este sentido, el conde de Haro ordenó que la documentación que se conservaba en su alcázar de Medina de Pomar se guardase:

en la manera que dicha es en el dicho alcáçar en dos arcas en que están, de que tengan el dicho Sancho Ferrandes de cada una arca una llabe, e Juan Ferrandes de Melgar, mi secretario, otra, en tanto

\footnotetext{
${ }^{24}$ Así ocurrió también en los archivos municipales, como explican García, Fernández 1999, p. 109. Por ejemplo, el duque del Infantado pidió que se buscasen "en las arcas e archibos del conçejo desa dicha çibdad [de Segovia]" ciertos documentos relativos al término del Real de Manzanares, de donde era señor. En AGS, RGS, leg. 149607, f. 85. Fechado el 6 de julio de 1496.

${ }^{25}$ Gómez 2011, p. 96.

${ }^{26}$ Ibidem, p. 99. El contenido misceláneo de estas arcas puede verse en AHNob, OSUNA, C.1831, olim leg.1831-2, sin foliar. Fechado el 15 de enero de 1456.

${ }^{27}$ AHNob, OSUNA, C.1831, olim leg.1831-2, sin foliar.

${ }^{28}$ Ibidem.

${ }^{29}$ De "barreta": afianzar o asegurar un baúl, un cofre, un cajón, etc. con barras de metal o de madera. En AHNob, OSUNA, C.1829, olim leg. 1829-11, sin foliar.
} 
que yo probeo de la tenençia del dicho alcáçar a la persona que entienda que cunple e me pluguiere ${ }^{30}$.

También se sabe que don Fadrique Álvarez de Toledo, duque de Alba, dispuso en 1530 que todas las villas de sus estados habrían de tener un arca destinada a archivo que dispusiese de tres llaves, que se repartirían entre la justicia, un regidor y el escribano del concejo, siguiendo las recomendaciones de la Pragmática Real de 9 de junio de $1500^{31}$. Otro testimonio más tardío mencionaba otra arca encorada en cuero castaño con foja de Flandes, con su çerradura y llave, y en cuyo interior había un libro de cuentas ${ }^{32}$; y otras dos arcas blancas con sus çerraduras y llaves que tiene libros $^{33}$. Como puede verse, la existencia de varias cerraduras y llaves implicaba la presencia de distintas personas en el momento de apertura del arca, con lo que se conseguía mayor seguridad en la consulta de la documentación ${ }^{34}$.

De todos estos testimonios se extrae que las arcas de archivo normalmente se construían en madera de pino o nogal y que se reforzaban con elementos metálicos. También disponían de distintas cerraduras de seguridad y asas para facilitar su transporte. La forma del mueble solía ser rectangular, con un tamaño variable, aunque siempre se garantizaba su movilidad aún estando llenas de documentos, razón por la cual tampoco debieron ser excesivamente grandes. Incluso es posible que llevasen grabadas las armas de la familia u otros elementos decorativos ${ }^{35}$.

Pero aunque la mayor parte de la documentación señorial se conservara en arcas de madera, también se utilizaron otros contenedores de diferentes formas y tamaños. Uno de ellos eran los portacartas, que eran pequeños contenedores con apariencia de caja o cofrecillo que se utilizaban para guardar correspondencia o papeles sueltos ${ }^{36}$. Hay un testimonio que menciona ciertas escripturas que están en el portacartas, en la fortaleza de Oterdehumos

${ }^{30}$ AHNob, FRÍAS, C.253/2, f. 13v.

${ }^{31}$ García, Fernández 1999, p. 46.

${ }^{32}$ AHNob, BAENA, C.82, D.21, ff. 10r y 10v. Fechado en 1558.

${ }^{33}$ Ibidem, f. 14r.

34 "El mobiliario construido al efecto en forma de arcas, cajones, armarios, dotados de un número específico de cerraduras, cuyas llaves sólo se encuentran a disposición de un número todavía más reducido de personas, denota la preocupación por la conservación", Navarro 2003, p. 89.

${ }^{35}$ García, Fernández 1999, p. 124. En relación a las armas familiares, en el Archivo Histórico de la Nobleza se conservan 78 baúles de madera con herrajes que en su día se remitieron desde el castillo de Montemayor (Córdoba) y en los que estuvo guardado el primitivo archivo de los duques de Frías. Los baúles tienen los escudos heráldicos de diferentes familias vinculadas con la Casa ducal de Frías.

${ }^{36}$ Rodríguez 2006, p. 278, voz: "portacartas”. Los portacartas de esta época eran seguros, resistentes y con una decoración a la moda que permitía lucirlos sobre las mesas de los estudios. 
$[\mathrm{sic}]^{37}$. Y otro que recoge que dentro de cierta arca de cuero negro había un portacartas barrado de hierro, de traer dineros, con su çerradura y llave. Puesto qués del dinero tiene algunas escripturas que se an de poner por ynventario $^{38}$.

Además podían utilizarse escrivanías de asiento, que eran una especie de caja-escritorio portátiles con pie incorporado y con compartimentos en su interior ${ }^{39}$. Una de las que se menciona tenía una estructura con unas barras doradas con su çerradura y llave, que tiene escripturas que se an de poner por ynventario. Están dentro unas tixeras y un par de cuchillos dorados, y un sello de plata ${ }^{40}$.

También aparecen mencionados, aunque en menor proporción, otros contenedores como los bargueños, los sacos, las bolsas o las talegas de lienzo o lino. Así, en cierto inventario se cita que fallose más en un talegón çiertas cartas de venta en pergamino de çiertas compras que se fisieron en Colindres e en Liendo ${ }^{41}$; y que había un talegón de lino [con] çiertas escripturas menudas $^{42}$; en otro se habla de una talega de lienço con papeles escriptos viejos ${ }^{43}$. Por último, se conserva una entrada que alude a dies e seys cartas de reyes escriptas en papel e selladas con çera, metidas en una bolsa de pergamino ${ }^{44}$.

\subsection{Agrupaciones documentales}

La documentación depositada en arcas y cofres de archivo podía instalarse de dos formas: la primera, mediante el apilado independiente de los documentos, siguiendo un orden cronológico de acumulación y ordenación. De este modo, la documentación más moderna quedaba ubicada en la parte superior del arca, ya que normalmente era la que se utilizaba con más frecuencia. En este sentido, es sintomático que en torno al año 1438 se realizase una averiguación para saber quién había accedido al arca de documentos del

Tenían anillas a los lados por las que se pasaba una cuerda que permitía llevarlo colgado en el cinto, los hombros o un animal de carga, Piera 2012, p. 162.

${ }^{37}$ Es decir, en Tordehumos (Valladolid). En AHNob, OSUNA, C.1829, olim leg. 1829-11, $\sin$ foliar.

${ }^{38}$ AHNob, BAENA, C.82, D.21, f. 11r. El barreado de hierro era una guarnición metálica de refuerzo consistente en barras de metal paralelas que se claveteaban sobre una superficie para darle mayor protección. En Rodríguez Bernis 2006, p. 61, voz: "barreado".

${ }^{39}$ Véase Castro 1921, p. 350; y Rodríguez Bernis 2006, p. 161, voz: "escribanía".

${ }^{40}$ AHNob, BAENA, C.82, D.21, f. 11v.

${ }^{41}$ AHNob, FRÍAS, C.253/2, f. 9r.

${ }^{42}$ Ibidem, f. 11v.

${ }^{43}$ AHNob, BAENA, C.82, D.21, f. 14r.

${ }^{44}$ AHNob, FRÍAS, C.1253, D.12, f. 2r. Fechado el 8 de marzo de 1459. 
monasterio de San Clemente de Toledo para echar dentro en ella, çerca del suelo, el dicho testamento falso a fin que paresçiese que avía grande tiempo que estava allit5.

La segunda y más habitual forma de instalación de la documentación, que además era perfectamente compatible con la anterior, era la de conformar "envoltorios" u otras agrupaciones físicas establecidas con una finalidad de organización y/o conservación. Los envoltorios fueron la unidad de instalación por excelencia en los archivos señoriales bajomedievales. Debieron ser el antecedente más inmediato de los legajos ya que, como veremos más adelante, desde mediados del siglo XVI ambos vocablos se utilizaron indistintamente para referirse a un mismo tipo de unidad de instalación ${ }^{46}$.

Los envoltorios se formaban con un pliego de papel o tela que envolvía, como su nombre indica, una agrupación de documentos. Estas unidades de instalación facticias se ataban y afianzaban con una cuerda de lino o cáñamo, lo que además facilitaba su manipulación y traslado ${ }^{47}$. En los inventarios conservados se mencionan, por citar algunas de las numerosas entradas registradas $^{48}$ :

otras dies cartas pequeñuelas escriptas en papel e enbueltas en un enboltorio de papel ${ }^{49}$;

un enboltorio de honse cartas de reyes escriptas en papel e selladas con su sello de çera ${ }^{50}$;

un enboltorio de escripturas de papel $^{51}$;

estas XV escripturas fasta aquí están en un enboltorio ${ }^{52}$.

Una vez formado el envoltorio era habitual que se colocase en la cabeça del mismo una cartela con información relativa a su contenido. En un inventario de finales del siglo XV leemos el apunte de que todas estas escripturas susodichas están en un enboltorio, y dize ençima: escripturas de Castrillo de Villavega ${ }^{53}$.

\footnotetext{
${ }^{45}$ AHNob, FRÍAS, C.1778, olim leg. 1031/28.

${ }^{46}$ Véase el inventario de la contaduría del estado de Béjar, Ayamonte y Gibraleón del año 1544, en AHNob, OSUNA, C.221, D.58. Uno de los escribanos que confeccionó este inventario, por ejemplo, utilizó ambos términos simultáneamente.

${ }^{47}$ García, Fernández 1999, p. 135.

${ }^{48} \mathrm{El}$ inventario de escrituras conservadas en la fortaleza de Medina de Pomar está cuajado de referencias a envoltorios y a su contenido. En AHNob, FRÍAS, C.253/2.

${ }^{49}$ AHNob, FRÍAS, C.1253/12, olim leg. 509/8, f. 2v.

${ }^{50}$ Ibidem, f. 3 r.

${ }^{51}$ Ibidem, f. 4v.

${ }^{52}$ AHNob, FRÍAS, C.253/2, f. 11v.

${ }^{53}$ AHNob, OSUNA, C.1829, olim leg. 1829-11, sin foliar.
} 
Y en el mismo inventario se mencionan cuatro envoltorios más de cuyos documentos se dice que están en los enboltorios que tiene su señoría de mi señora doña Mencía de la Vega en un cofre pequeño barreado, e tiene en cada enboltorio un memorial fecho ${ }^{54}$.

En este sentido, testimonios posteriores confirman que a mediados del siglo XVI seguían confeccionándose cartelas con la información del contenido de los envoltorios, práctica que aún habría de prolongarse en el tiempo durante varios siglos:

Un enboltorio que dize ençima de letra del contador Juan Núñez: aquí están títulos de Carmona, hallados en la escriptura de mi señora a [ilegible] tomar recaudo ${ }^{55}$.

Un enboltorio grande que dize ençima: en este pliego hallarás el ynbentario de todas las escripturas que están en este enboltorio y son y tocan a la casa de Béjar ${ }^{56}$.

Por los datos recogidos en estas cartelas puede deducirse que los envoltorios agrupaban documentos con afinidad temática, geográfica o incluso cronológica. Por ejemplo, todas las escrituras relativas a lugar de Castrillo de Villavega (Palencia) se agrupaban en:

un enboltorio de çiertas cartas mensageras e libramientos del señor don Diego, e conoçimientos de los maravedíes que reçebió de mi señora, e un escripto que presentó Juan de Haro en nombre de mi señora e requerió a don Pedro sobre la fortaleza e villa de Castrillo, e lo que respondió el dicho don Pedro en otro escripto ${ }^{57}$.

Del mismo modo, un inventario de las escrituras del alcázar de Medina de Pomar también refleja la afinidad geográfica de la documentación que se encontraba en otro enboltorio [con] çiertas escripturas e cartas de Castilla $V i e j a^{58}$. Un último ejemplo de agrupación temática de documentos lo ofrece el testimonio de un enboltorio de lo que se gastó en las obras de Lepe, año de DXXVI ${ }^{59}$.

En cuanto a los legajos, es interesante señalar que el término no aparece mencionado en los inventarios consultados hasta mediados del siglo XVI. Todo apunta a que el legajo fue la evolución natural del envoltorio. De

\footnotetext{
${ }^{54}$ AHNob, OSUNA, C.1829, olim leg. 1829-11, sin foliar.

${ }_{55}^{55}$ AHNob, OSUNA, C.221, D.58, f. 8v.

${ }_{56}$ AHNob, OSUNA, C.221, D.58, f. 9v.

57 AHNob, OSUNA, C.1829, olim leg. 1829-11, sin foliar.

${ }^{58}$ AHNob, FRÍAS, C.253/2, f. 5v.

${ }^{59}$ AHNob, OSUNA, C.221, D.58, f. 9r
} 
hecho, el propio vocablo procedía del verbo "ligar" y fue definido a principios del siglo XVII por Sebastián de Covarrubias como los papeles entre sí sueltos, que están atados con alguna cuerda o lía, y assí se dize a ligando. En los archivos tienen éstos sus números por do fácilmente se halla una escritura ${ }^{60}$.

Los legajos conservaron la afinidad temática de los envoltorios. Por ejemplo, en un inventario de 1544 se mencionan ciertas escripturas de tributose deudas de los marquesados en un legajo; y también se recoge otro legajo de cosas de lo de la guerra ${ }^{61}$. En otro inventario se citan algunos arrendamientos e escripturas que tocan a la hazienda de Castilla, en un legajo ${ }^{62}$.

Las cartelas de los legajos, como ocurría con las de los envoltorios, se confeccionaban generalmente en papel con algún documento inservible plegado varias veces y encolado para aumentar su consistencia (lo que se denominaba "papelón") y en el que se escribía con cuidada caligrafía un resumen del contenido del legajo. En estas cartelas podía leerse:

Castrillo [de Villavega]. Cajón 11. Legajo 1: Títulos de pertenencia de la villa de Castrillo y de su escribanía, y otras rentas ${ }^{63}$.

Castrillo de Villavega, Tordehumos. Cajón 11. Legajo 3. Títulos de la villa de Tordehumos y heredades de Villabrágima y otros ${ }^{64}$.

Los inventarios también mencionan "atados" y "atadillos", que seguramente fuesen envoltorios o legajos de menor entidad y en los que igualmente se utilizaban cuerdas de cáñamo o simples hilos para sujetar y afianzar la documentación. En un testimonio del año 1459 se mencionan siete cartas escriptas en papel e selladas con çera (...) Van atadas con un filo prieto ${ }^{65}$; y otro del año 1544 se citan ciertos acostamientos de la marquesa, mi señora, del año de DXXXV, en seys quadernos atados con una trença $[\mathrm{sic}]^{66}$. Del mismo modo, en un inventario del año 1558 se consigna que había un papel atado con un hilo, que están dentro conoçimientos e cartas de pago de los juros de la villa de Villor ${ }^{67}$, aunque hay otro testimonio que recoge varios procesos en

${ }^{60}$ Riquer 2003, p. 757, voz: "legajo".

${ }^{61}$ AHNob, OSUNA, C.221, D.58, f. 8r.

${ }^{62}$ Ibidem, f. 9r.

${ }^{63}$ AHNob, OSUNA, C.1829, sin signaturar. La cartela, aunque escrita con tipos góticos, debió confeccionarse en el siglo XVII.

${ }^{64}$ AHNob, OSUNA, C.1831, sin signaturar. La cartela tiene las mismas características que la anterior.

${ }^{65}$ AHNob, FRÍAS, C.1253/12, olim leg. 509/8, f. 3r. En este caso, el "filo prieto" puede referirse a un hilo atado y apretado o a un hilo de color negro.

${ }^{66}$ AHNob, OSUNA, C.221, D.58, f. 9r.

${ }^{67}$ AHNob, BAENA, C.82, D.21, f. $16 r$. 
este envoltorio cosido y acomulado con la ynformaçión prençipal ${ }^{68}$, es decir, que estaban cosidos formando una única unidad.

Otra forma específica de agrupar documentos que empezó a utilizarse durante la Baja Edad Media y que continuó utilizándose en los siglos posteriores fue la de los pliegos horadados, que se conformaban uniendo varios pliegos de papel y cosiéndolos con una cuerda de cáñamo a través de un agujero situado en el tercio superior izquierdo del folio. Para ello, el pliego era previamente doblado por ese lugar para facilitar que se practicase un corte semicircular que, al desdoblarse el pliego, se convertía en un agujero circular simétrico por el que se pasaba la cuerda. Con este sencillo sistema se conseguía agrupar documentación seriada cuyo volumen final resultaba imprevisible, como ocurría con los registros de la cancillería real o con los cuadernos de rentas de los oficiales encargados de la Contaduría señorial.

Los archivos señoriales conservan numerosos ejemplos de pliegos horadados o "de cordel" entre la documentación de carácter económico. Tenemos los ejemplos de las cuentas del condado de Oropesa del año $1449^{69}$; las cuentas de las rentas del peso, del pan y de las alcabalas de la villa de Villalón de Campos del año $1483^{70}$; las cuentas del estado de Alba de Liste de los años 1485 a $1523^{71}$; o la postura de las rentas de los estados de Benavente correspondiente al año $1493^{72}$. Una noticia contenida en un inventario de la Contaduría de los estados de Béjar, Ayamonte y Gibraleón del año 1544 menciona unos pliegos horadados de letra de Juan de Çuola, de rentas de los marquesados $^{73}$, lo que evidencia que este sistema continuaba en uso en los archivos señoriales una centuria después de los primeros testimonios sobre su utilización.

Pero también existieron cosidos más sencillos para unir documentación que, por norma general, guardaba estrecha relación entre sí. Un testimonio del último cuarto del siglo XV hacía referencia al cosido de varios traslados de mercedes sobre la carta del sello que el señor rey don Juan hyzo al señor don Diego, concretamente sobre la merindad de Carrión y sobre la Peña de Amaya, que eran de temática similar y que están todas tres cosidas juntas $^{74}$. Sin embargo, este tipo de cosidos no debieron ser frecuentes entre la documentación señorial.

\footnotetext{
${ }^{68}$ AHNob, OSUNA, C.873, D.84. Fechado ca.1557.

${ }^{69}$ AHNob, FRÍAS, C.1098, D.2.

${ }^{70}$ AHNob, OSUNA, C.525, D.83.

${ }^{71}$ AHNob, OSUNA, C.869, D.21-22.

${ }^{72}$ AHNob, OSUNA, C.417, D.168.

${ }^{73}$ AHNob, OSUNA, C.221, D.58, f. 7v.

${ }^{74}$ AHNob, OSUNA, C.1829, olim leg. 1829-11.
} 
Un último dato que resulta muy llamativo y que se aprecia en algunos inventarios de contabilidad de comienzos del siglo XVI es el de la equivalencia de los términos envoltorio, legajo y cuaderno con el de libro. El vocablo "libro" había designado tradicionalmente qualquier volumen de hojas, o de papel o pergamino ligado en quadernos y cubierto $^{75}$, entendiendo por ello el conjunto de hojas unidas entre sí, fuese cual fuese su volumen, y protegidas por unas cubiertas o tapas. Estas guardas se elaboraban con el objeto de ayudar a la conservación del documento mediante la protección de su soporte, sobre todo cuando éste era papel, aunque con el tiempo adquirieron también una función ornamental. Hay dos testimonios de mediados del siglo XV en el que ya se mencionan dos libros en el correspondiente archivo señorial:

Un libro viejo del estado de Çúñiga del año de [mil cuatrocientos] çinquenta e quatro e çincuenta e çinco. Prinçipalmente ay ynventario de escripturas ${ }^{76}$.

Un libro antiguo del tiempo del conde de Plazencia que se començó [en el] año de mill e quatroçientos e çinquenta e siete ${ }^{77}$.

En 1461 también se encuentran referencias a un libro grande escripto en papel e cubierto de pergamino ${ }^{78}$, aunque normalmente los libros se citan en los inventarios sin más detalle que el de veynte e tres libros enquadernados de los marqueses, mis señores ${ }^{79}$; catorze libros chicos tanbién enquadernados ${ }^{80}$; o dos libros viejos con cubiertas de pergamino del tiempo de los marqueses, mis señores ${ }^{81}$.

Saber a ciencia cierta si estos libros eran envoltorios, legajos, pliegos horadados o libros de lectura propiamente dichos es cuestión compleja, ya que a lo largo de uno de los inventarios conservados aparecen referenciados diversos envoltorios, legajos y libros cuya tipología se resume en un último párrafo con la frase: todos los quales dichos libros, e cada uno dellos, y escrituras que de suso se faze minçión se dieron y entregaron ${ }^{82}$.

\footnotetext{
${ }^{75}$ Riquer 2003, p. 765, voz: "libro".

${ }^{76}$ AHNob, OSUNA, C.221, D.58, f. 7v.

${ }^{77}$ AHNob, OSUNA, C.221, D.58, f. 7r.

${ }^{78}$ AHNob, FRÍAS, C.253/2, f. 21v.

${ }^{79}$ AHNob, OSUNA, C.221, D.58, f. 9r.

${ }^{80}$ Ibidem.

${ }^{81}$ Ibidem.

${ }^{82}$ Ibidem.
} 


\subsection{Otras formas de instalación}

Una de las prácticas archivísticas seguidas habitualmente en los archivos señoriales fue la del plegado de los pergaminos de gran formato. Los documentos escritos sobre este soporte, que normalmente eran demasiado grandes para ser conservados en los envoltorios o legajos que se iban confeccionando, eran plegados varias veces sobre sí mismos hasta ser reducidos al tamaño del folio de papel. Esta forma de instalación servía como medida de protección de los sellos pendientes, que habitualmente eran alojados dentro de sus dobleces ${ }^{83}$. Pero además, con este nuevo formato, los pergaminos podían guardarse con mayor facilidad en los cajones de las escribanías, bargueños o demás mobiliario de archivo que se utilizaba a la sazón ${ }^{84}$.

No se tiene constancia del momento en que se iniciaron estas prácticas tan corrientes durante todo el siglo XVI y siguientes. En un inventario fechado en 1444 se cita una sentençia escripta en pergamino en tres pieles $\operatorname{largas}^{85}$, que seguramente, y debido a su tamaño, tuvo que ser plegada para su instalación en su correspondiente arca. Sin duda alguna, el reducido tamaño de las arcas de archivo fue la causa principal de la incorporación de estas medidas.

Incluso en otras ocasiones los pergaminos plegados en origen se aplanaban y volvían a plegar posteriormente para adecuarlos al tamaño del resto de las escrituras de la unidad de instalación. Un ejemplo de ello lo constituye un privilegio de confirmación otorgado en 1432 por el rey Juan II a don Pedro Fernández de Velasco, conde de Haro, sobre ciertos maravedíes de juro situados en la ciudad de Burgos, que si bien en principio estaba doblado en billete más tarde fue extendido y plegado en tres partes para adaptarlo al tamaño del legajo correspondiente ${ }^{86}$.

\subsection{Conservación de la documentación señorial}

Independientemente del volumen que tuviese cada archivo señorial, es seguro que desde los inicios se siguieron unas prácticas de conservación para que la documentación se mantuviese siempre en el mejor estado. Puede decirse que los oficiales señoriales aplicaron medidas de conservación básicas pero efectivas cuyo mejor exponente es el enorme caudal de documentación de origen señorial que ha llegado hasta nuestros días.

\footnotetext{
${ }^{83}$ García, Fernández 1999, p. 152.

${ }^{84}$ Gómez, en prensa.

${ }^{85}$ AHNob, FRÍAS, C.1252/33, olim leg. 508/22. Fechado el 16 de diciembre de 1444.

${ }^{86}$ AHNob, FRÍAS, C.597/26.
} 
Las medidas de conservación de las que se tiene constancia fueron sobre todo de tipo preventivo. Estas medidas se aplicaron sobre todo a los contenedores de documentos, tal y como atestigua la referencia a un arca de madera forrada por de dentro en lienço ençerado ${ }^{87}$, que era un método de impermeabilización utilizado para proteger los documentos de la humedad ambiental $^{88}$.

Pero también se realizaron acciones sobre algunos documentos singulares con el objetivo de reforzarlos y protegerlos de la manipulación. La acción más frecuente, sencilla, rápida y barata para proteger directamente la documentación fue la de confeccionar encuadernaciones flexibles en pergamino. Las referencias a los documentos encuadernados son escuetas, como el inventario que menciona dos escripturas de papel fechas en quaderno cubiertas con una cubierta de pergamino ${ }^{89}$; o el que cita un libro de las cuentas de Villora, con su covertor de pergamino ${ }^{90}$. En muchas ocasiones, los pergaminos utilizados como tapas en la encuadernación eran documentos reutilizados y que ya habían perdido su validez jurídica. En estos casos, la parte escrita se colocaba hacia el interior de la encuadernación, reservándose la parte no escrita como cubierta para escribir el título y otras anotaciones relativas al contenido del documento encuadernado ${ }^{91}$.

También se realizaron encuadernaciones en cuero, que eran más resistentes y elaboradas que las de pergamino. La principal diferencia entre estos dos tipos de encuadernación residía en la ejecución o no de un proceso de curtimiento de la piel, cuyo resultado dotaba al cuero de mayor resistencia y estabilidad ante el agua que el pergamino sin curtir $^{92}$.

Las encuadernaciones en cuero eran empleadas para proteger documentos de mayor importancia o de manejo más habitual. Se conservan dos magníficos epistolarios de Íñigo López de Mendoza Quiñones, II conde de Tendilla y Capitán General de la Alhambra de Granada, encuadernados en forma "de cartera" ${ }^{93}$. Este tipo de encuadernación se componía de unas tapas de piel que contenían un núcleo de papelón, esto es, el cartón que se formaba mediante el encolado y prensado de hojas de papel, lo que le otorgaba mayor consistencia. En la decoración de las tapas se emplearon diferentes motivos

${ }^{87}$ AHNob, FRÍAS, C.1253/12, olim leg. 509/8, f. 1r.

${ }^{88}$ Piera 2012, pp. 161-162.

${ }^{89}$ AHNob, FRÍAS, C.1253/12, olim leg. 509/8, f. 3r.

${ }^{90}$ AHNob, BAENA, C.82, D.21, f. 10v.

${ }^{91}$ Véase un ejemplo en AHNob, OSUNA, C.1829, olim leg. 1829-11.

${ }^{92}$ Tacón 2011, p. 98.

${ }^{93}$ AHNob, OSUNA, C.3406, D.1, fechado entre 1504 y 1506; y ibidem, D.2, fechado entre 1513 y 1515 . En las hojas sueltas que acompañan a ambos libros se recogen numerosas relaciones de documentos llevados por los correos a la Corte y a otros lugares. 
geométricos que posteriormente evolucionaron hacia tipologías de mayor complejidad y suntuosidad ${ }^{94}$.

Además, se han conservado curiosos ejemplos de documentos solemnes escritos en pergamino y encuadernados con tapas de madera recubierta con cuero. Uno de ellos, en mal estado de conservación debido precisamente al deterioro de la madera de sus cubiertas, es la copia del testamento de don Juan de Silva y de su mujer doña Juana Enríquez, señores de Chamusca y Ulme, encuadernado en piel y rematado con cantoneras y cierre metálicos labrados ${ }^{95}$.

\subsection{Copias y traslados}

Otra práctica cotidiana que supuso una verdadera forma de preservación de la documentación fue la elaboración de copias y traslados de documentos originales. La dispersión de los fondos patrimoniales a que aludimos más arriba favoreció la proliferación de extractos de documentos, copias simples de los mismos o traslados autenticados por escribanos para poder disponer de la información de los documentos que habitualmente se encontraban en otros estados del mismo señor ${ }^{96}$. En un inventario de mediados del siglo XV encontramos una referencia a un enboltorio de traslados de las cartas originales que Juan de Velasco tiene sobre el ofiçio de la merindad de Castilla Vieja ${ }^{97}$; y también a otro enboltorio de escripturas de copia de pedido de las merindades de Bureba e Rioja e Villadiego ${ }^{98}$, lo que constituyen buenos ejemplos de unas prácticas que siguieron empleándose a lo largo de los siglos siguientes.

\section{ORGANIZACIÓN Y DESCRIPCIÓN DE LA DOCUMENTACIÓN SEÑORIAL}

La documentación señorial castellana bajomedieval tuvo una organización y descripción básica y muy sencilla que constituyó la base para el desarrollo de nuestras prácticas archivísticas actuales. No se han conservado, que sepamos, instrucciones medievales relativas a la organización de estos archivos en Castilla, pero puede suponerse que el propio titular de la documentación fue quien impuso sus criterios en todo lo relacionado con el tratamiento

\footnotetext{
${ }^{94}$ Gil, Gómez 2009, pp. 108-113.

${ }^{95}$ AHNob, OSUNA, C.2207, D.9. Fechado el 15 de febrero de 1520.

${ }^{96}$ Gómez Vozmediano 2012, p. 266.

${ }^{97}$ AHNob, FRÍAS, C.253/2, f. 21 r.

${ }^{98}$ Ibidem.
} 
de sus archivos ${ }^{99}$, sobre todo en los señoríos de menor entidad, y que en todo caso estaría auxiliado por un secretario o algún oficial similar ${ }^{100}$.

Las primeras propuestas e iniciativas en materia de organización de archivos se orientaron hacia el desarrollo de instrumentos de descripción más o menos complejos en función del volumen del archivo y del número de sus documentos. Estos primitivos trabajos se caracterizaban por su dependencia con respecto a los instrumentos de consulta y control de la documentación, ya que un código o signatura remitía al lugar de ubicación de la misma ${ }^{101}$.

La forma de organización de la documentación más frecuente fue la clasificación por materias, con expresión de la tipología documental. De todos modos, cualquier organización del archivo tuvo su reflejo en los inventarios existentes y, durante los siglos XVI y XVII, también en las propias piezas documentales, en las que se añadieron las anotaciones alfanuméricas necesarias para su inmediata localización ${ }^{102}$.

De esta manera, puede asegurarse que la organización de los archivos señoriales, aunque fue simple, cumplió con eficacia el objetivo de localizar al momento la documentación que se necesitaba. Los frecuentes testimonios de peticiones de documentos para su traslado o entrega a terceros llevan a pensar en que además existió una gestión eficiente de los archivos de los señoríos, ya que las escrituras se localizaban con rapidez gracias a los instrumentos de descripción compuestos a tal efecto.

\subsection{Inventarios}

El instrumento de descripción más extendido desde mediados del siglo XV fue el inventario, que también aparece mencionado con los términos de "remembrança"103, "índice", "memorial”, "relación”, "catálogo", "abecedario" o "sumario"104. El número de documentos conservados en las arcas de los archivos señoriales era tan reducido que nunca hubo necesidad de confec-

${ }^{99}$ Véanse las interesantes instrucciones de gobierno elaboradas por el condestable de Castilla en septiembre de 1645. Estas instrucciones constituyen un auténtico manual para la gestión del archivo de la Casa de Frías, y tal vez fuesen copia de prácticas archivísticas anteriores. En AHNob, FRÍAS, C.634/17, ff. 24v-28r. Recientemente se ha publicado un artículo sobre las mismas. Véase Cuesta 2014, pp. 179-203. Véanse las pp. 184-188 para todo lo relativo a la Contaduría; y las pp. 188-189 para las recomendaciones que debían aplicarse sobre el archivo de la Casa.

${ }^{100}$ Así ocurría en el caso del condado de Montalbán. Véase Flores 1997, p. 44.

${ }^{101}$ Navarro 2003, pp. 145-146.

${ }^{102}$ Ibidem, pp. 146-147.

${ }^{103}$ Así aparece en AHNob, FRÍAS, C.253/2.

${ }^{104}$ García, Fernández 1999, p. 239. 
cionar complejos inventarios. De hecho, los documentos solían citarse en virtud de su tipología documental, de su contenido y de sus caracteres externos más llamativos. Se sabe que en los archivos municipales, por ejemplo, los inventarios de esta época abarcaban un número de legajos que no superaba el centenar y un número de documentos generalmente inferior al millar ${ }^{105}$.

Las descripciones contenidas en los inventarios eran someras y reseñaban el contenido de los documentos muy brevemente. Cada entrada solía encabezarse con la tipología documental, ya fuese jurídica o diplomática. En ocasiones también se especificaba el monarca o pontífice que había otorgado el documento. El destinatario no se mencionaba, ya que normalmente era el propio señor. Tampoco solían referenciarse las datas tópica o crónica.

Las referencias explícitas a la localización del documento en cuestión solían ser muy sucintas. Lo habitual era que en los inventarios se citasen los distintos envoltorios de documentos ordenados por una letra del alfabeto latino, como en el inventario de las escrituras de la fortaleza de Tordehumos de finales del siglo $\mathrm{XV}$, en el que se señalaban los envoltorios marcados con las letras "h", "f", "d" y "g". El hecho de utilizar letras en vez de números corridos como criterio de ordenación de las unidades de instalación indica que el archivo no debía tener un gran tamaño ${ }^{106}$. Tampoco parece que los documentos estuviesen ordenados dentro de los envoltorios, ya que de otro modo en los inventarios se habrían conservado referencias de localización adicionales.

Otro dato interesante que se aprecia en el análisis de los inventarios conservados es que los encargados de realizarlos, normalmente escribanos o secretarios señoriales, poseían sólidos conocimientos de diplomática. A comienzos del siglo XVI, por ejemplo, el condestable Íñigo Fernández de Velasco, duque de Frías, recibió de Hernando de Pereda, mayordomo del conde de Ureña, ciertas escrituras relativas a la merced de la posesión de Gibraltar. El encargado de confeccionar la minuciosa relación de documentos que fueron entregados reseñó sus caracteres externos y también la tipología documental de la cancillería real. De este modo, se citaba un:

Previllejo del rey (...) escripto en un cuaderno de pergamino con su sello de plomo pendiente.

Una carta del rey don Enrrique escripta en papel.

Una alvalá de merçed del rey (...) fecha en pergamino e sellada con su sello en las espaldas y fiermada de su nombre.

Una provisión y merçed del rey (...) escripta en papel.

Un previllejo rodado del rey (...) escripta en una piel de pergamino e sellada con su sello de plomo pendiente.

${ }^{105}$ Ibidem, p. 211.

${ }^{106}$ AHNob, OSUNA, C.1829, olim leg. 1829-11. 
Un traslado de previllejo del rey (...) escripto en pergamino e signado de escribano público con un sello de çera blanca pendiente en una çinta de lana verde.

Una escriptura de sentençia de deslindamientos de términos (...) escripta en un cuaderno de pergamino ${ }^{107}$.

Esta circunstancia contrasta con el desconocimiento que generalmente tenían los propios señores en esta materia, tal y como demuestra la petición realizada por Pedro Fernández de Velasco, conde de Haro, para que se buscase, entre otras escrituras:

Dios aya;

un juramento que fiso Pedro de Ayala a Juan de Velasco, que

un quaderno de quatro fojas de cómo pidió ayuda,

[y también] otra carta de pergamino signada de escribano de

la posesión que Juan Ferrandes de Valle tomó de Fresneda ${ }^{108}$.

Por otro lado, el hecho de que en los inventarios se utilizasen los asientos indistintamente para describir una simple carta o un número determinado de libros demuestra, y esto es igualmente interesante, que en el momento de la composición del inventario se producía una primera valoración de la documentación, lo que se manifestaba en ese diferente tratamiento descriptivo ${ }^{109}$. Pero a pesar de que no existiese uniformidad alguna en cuanto a la extensión o sistematización del contenido de los inventarios, los datos mínimos que contenían fueron siempre suficientes para localizar los documentos que requería su titular.

\subsection{Cartularios y registros}

En estrecha relación con los inventarios se encontraban los cartularios que, sin tener la consideración de instrumentos de descripción stricto sensu, fueron herramientas auxiliares que también aportaban información extensa del contenido de la documentación conservada en el archivo ${ }^{110}$. Desde mediados del siglo XIV, coincidiendo con la Peste Negra y la crisis subsiguiente, los oficiales encargados de los archivos señoriales copiaron las prácticas archivísticas que seguían las instituciones eclesiásticas en materia de

\footnotetext{
${ }^{107}$ AHNob, FRÍAS, C.601/39, olim leg. 181/28. Fechado el 25 de mayo de 1515.

${ }^{108}$ AHNob, FRÍAS, C.597/48, olim leg. 179/28. Fechado el 25 de febrero de 1451.

${ }^{109}$ Eso mismo ocurre en el inventario de la documentación municipal de Astorga, fechado en el año 1447. En García, Fernández 1999, p. 220.

${ }^{110}$ El trabajo más completo sobre cartularios sigue siendo el de Chastang 2001.
} 
conservación y comenzaron a elaborar cartularios ${ }^{111}$. Estos libros copiadores evitaban que los documentos originales tuviesen que ser sacados del arca de archivo cada vez que eran necesarios y, en muchas ocasiones, incluso llegaron a autenticarse las copias con objeto de que tuviesen plena validez jurídica ${ }^{112}$. A ello se unía la mayor comodidad en el manejo de los cartularios debido a su formato en códice frente a los documentos en pergamino de gran formato, difícil manejo o peor lectura. En estos libros normalmente se utilizaba una escritura gótica libraria bien ejecutada, lo que facilitaba enormemente la comprensión del texto ${ }^{113}$.

Se ha conservado un precioso cartulario en octavo encuadernado en pergamino y fechado en 1345 con la copia de una docena de documentos relativos a la jurisdicción del Monasterio de Santo Domingo de Silos, en Burgos $^{114}$. También se ha conservado otro volumen con el mismo formato que el anterior, pero realizado en el último cuarto del siglo $\mathrm{XV}$, que contiene una copia simple de diferentes documentos relativos a doña Mencía de la Vega y a su segundo esposo don Bernardino de Quiñones, conde de Luna, sobre asuntos tocantes a las villas de Castrillo de Villavega (Palencia) y Tordehumos (Valladolid) ${ }^{115}$. Por último, otro cartulario conservado es el registro de privilegios y escrituras relativas a diferentes lugares de los estados del ducado del Infantado ${ }^{116}$. Con esmerada minuciosidad, imitando incluso la lengua, escritura, disposición del texto, signos, firmas y sellos de los documentos originales, en este último cartulario se copiaron y compilaron fundamentalmente privilegios reales sobre distintos asuntos, aunque no faltan curiosidades como las copias de algunas cartas enviadas por el rey de Francia al Almirante de Castilla, fallos judiciales, apuntes genealógicos o dichos populares castellanos. Tanto es así que en una de sus páginas se puede leer una simpática nota que dice: este libro es muy bueno y tiene muy buenos cuentos y refranes ${ }^{117}$.

Se ha apuntado con gran acierto que estos cartularios deben ser observados desde el prisma de haber funcionado como reflejo de la ordenación de los archivos en el momento de su elaboración ${ }^{118}$, puesto que estaban precedidos de una tarea sistemática de selección y, en ocasiones, también de

${ }^{111}$ Gómez 2012,p. 264.

${ }^{112}$ Un buen ejemplo es el del Tumbo Viejo de la Catedral de Lugo, que está siendo estudiado en profundidad por Sánchez 2011, p. 81.

${ }_{113}^{113}$ García, Fernández 1999, pp. 163-164.

${ }^{114}$ AHNob, FRÍAS, C.85/18, olim leg. 33/20.

${ }^{115}$ AHNob, OSUNA, C.1829, olim leg. 1829-11.

${ }^{116}$ AHNob, OSUNA, C.3355, D.1. Sin foliar. Aunque el cartulario está fechado en la primera mitad del siglo XVI, la mayoría de las copias que contiene son del siglo XV.

${ }^{117}$ AHNob, OSUNA, C.3355, D.1. Sin foliar.

${ }^{118}$ Calleja 2014, p. 224. 
eliminación de los documentos originales que sirvieron para su confección ${ }^{119}$. No hay duda de que la investigación sobre estos instrumentos arrojará interesantes resultados sobre la organización de los archivos medievales que los emplearon.

En cuanto a los registros, el rey Alfonso X ya señaló en Las Partidas los beneficios de mantener un registro de escrituras. Para el monarca:

registro tanto quiere decir como libro que es hecho para remembranza de las cartas e de los privilegios que son hechos.

E han provecho porque si el privilegio o la carta se pierde, o se rompe o se deshace la letra por vejez, o por otra cosa, o si viniere alguna duda sobre ella por ser raída o de otra manera cualquiera, por el registro se pueden cobrar las pérdidas e renovarse las viejas ${ }^{120}$.

Los registros de la cancillería real castellana se han conservado seriados desde el último tercio del siglo XV y constituyen el denominado Registro General del Sello, bien estudiado en las últimas décadas ${ }^{121}$.

Sin embargo, no se conservan registros señoriales castellanos de esta época. La escasez de los mismos quizá responda precisamente a la inexistencia de una cancillería señorial como tal. A lo sumo, durante el siglo XV debieron existir prácticas cancillerescas entre algunos oficiales señoriales que copiaron las técnicas de la cancillería real, pero con la información que ha llegado hasta nosotros difícilmente puede hablarse de una oficina señorial dedicada exclusivamente a la producción documental. De hecho, en los inventarios aparecen menciones muy esporádicas a registros, y siempre relacionadas con documentación de naturaleza privada. En uno de ellos se cita:

un enboltorio de los registros de las cartas que se han de faser para Garçía Ferrandes, escribano sobrescrito, que él e Gonçalo Martines de Hanelos [sic] fesieron de la Casa de Cordovilla ${ }^{122}$.

Pero como durante todo el Antiguo Régimen las cartas despacharon indistintamente asuntos de toda índole, ya fuesen oficiales o personales, quizá debamos pensar en que los primeros registros señoriales comenzaron a funcionar utilizando esta tipología documental. En este sentido, el mejor ejemplo de

\footnotetext{
${ }^{119}$ Calleja 2002, p. 21.

${ }^{120}$ Partida Tercera, Título XIX, Ley VIII; Alfonso X, Las Siete Partidas, ed. Sánchez-Arci1la, pp. 527-528.

${ }^{121}$ Una aproximación a esta Sección del Archivo General de Simancas puede verse en Crespo, et al. 2001.

${ }^{122}$ AHNob, FRÍAS, C.253/2, f. 15r.
} 
un registro sistemático de correspondencia señorial fue el de Íñigo López de Mendoza Quiñones, II conde de Tendilla, de quien por fortuna se han conservado dos completos epistolarios en los que sus oficiales copiaron muchas de las cartas que envió mientras ostentó el cargo de Capitán General de la Alhambra de Granada a comienzos del siglo XVI ${ }^{123}$.

\section{CONCLUSIONES}

Una vez presentados todos los testimonios anteriores, que en su mayor parte han sido extraídos de documentación original datada en los siglos XV y XVI, es momento de recapitular brevemente cómo surgieron, cómo se organizaron y cómo funcionaron los archivos señoriales castellanos durante la Baja Edad Media.

Los archivos señoriales se crearon con la finalidad de conservar tanto las escrituras de la Cámara, es decir, los privilegios, donaciones y mercedes que probaban la titularidad del señor sobre determinados derechos patrimoniales; como las escrituras de la Contaduría, esto es, las que servían para administrar y gestionar las propiedades señoriales. Si bien la documentación de la Cámara dependía directamente del señor y de sus oficiales más fieles, la documentación de la Contaduría estaba a cargo de los oficiales encargados de estas tareas, fundamentalmente contadores y tesoreros, y en ocasiones llegó incluso a conservarse en sus residencias particulares.

En cualquier caso, lo fundamental era que todos estos documentos se pudiesen localizar con rapidez para atender cualquier demanda o gestión. Para hacerlo con la mayor eficacia, la documentación que afectaba a los dominios de un determinado territorio se custodiaba en la correspondiente fortaleza señorial. El alcaide, oficial delegado por el señor para gobernar cada fortaleza, era el encargado de administrar la documentación, y seguramente estaba auxiliado por los diferentes escribanos señoriales del entorno.

No existen evidencias para afirmar que durante el siglo XV hubiese estancias específicas de archivo dentro de las fortalezas. La documentación se guardaba en arcas de madera protegidas con cerraduras de hierro y distribuidas por los aposentos privados del titular. Portacartas, escribanías de asiento, cajitas de madera, bolsas y talegas fueron otros contenedores utilizados para guardar documentación, aunque no ofrecían las mismas condiciones de seguridad que las arcas de madera reforzadas con metal. La documentación

\footnotetext{
${ }^{123}$ Véase los ejemplos de AHNob, OSUNA, C.3406, D.1-2. Han sido publicados, respectivamente, por Szmolka, Moreno, Osorio 1996; Osorio, et al. 2007.
} 
era depositada en ellas de forma cronológica, es decir, las escrituras más antiguas permanecían en el fondo y las más recientes se colocaban encima. Podían guardarse independientemente, pero lo común era que se confeccionasen "envoltorios" con afinidad temática o cronológica.

Estos envoltorios se ordenaban siguiendo las letras del alfabeto, de lo que se deduce que el número total de envoltorios de cada archivo señorial no debió ser elevado. De otro modo, hubiese sido más práctico sustituir esas letras por números ordinales, como se hizo en los archivos señoriales de siglos posteriores. Los envoltorios solían estar marcados con una cartela identificativa en la que se recogía su contenido de forma sumaria. Además, estas agrupaciones se adaptaron al tamaño del folio castellano. La documentación en soporte diferente al papel, como los grandes pergaminos que contenían privilegios reales, solía plegarse y adaptarse a ese formato.

Otro tipo de agrupación empleada en los archivos señoriales fueron los pliegos horadados, normalmente utilizados para documentación de carácter seriado y de volumen final impredecible. Estas agrupaciones fueron muy habituales entre la documentación económica de la Contaduría.

Los oficiales de los archivos señoriales encuadernaron algunos documentos añadiéndoles unas tapas de pergamino o incluso de cuero. Este tratamiento se aplicaba a los documentos más importantes por motivos de conservación y, en ocasiones, también de suntuosidad, ya que algunas encuadernaciones estaban tan trabajadas que añadían un valor artístico y de solemnidad al texto que albergaban.

Por lo que respecta a la organización de los fondos, durante todo el siglo XV se asistió a una expansión del inventario de escrituras señoriales como instrumento descriptivo de la documentación. Gracias a ellos, los oficiales pudieron organizar y tener controlado el archivo señorial. Estos rudimentarios pero eficaces instrumentos respondieron con creces a las necesidades archivísticas de quienes utilizaban la documentación. Además, es importante destacar la pericia diplomática de los encargados de redactar los inventarios, ya que conocían y manejaban con soltura las tipologías documentales de la cancillería real y de las oficinas señoriales correspondientes. Los responsables de los archivos también compusieron cartularios para facilitar la utilización de la información que requerían sus señores.

La importancia de toda esta documentación hacía que se guardase un celo especial en su conservación y que sólo los oficiales que gozaban de la mayor confianza del señor pudiesen acceder a ella. De hecho, en algún caso incluso se llegó a pedir al Papa que dictase excomunión sobre aquellos que robaban escrituras, lo que es indicativo del nivel de protección que se daba a los archivos. Los frecuentes testimonios que se refieren al depósito de escrituras en manos de personas de la más elevada posición social o su aceptación como 
prenda en determinados préstamos de dinero son buena muestra del valor concedido a la documentación señorial.

Con todo, nos encontramos que en los señoríos de la Castilla del siglo XV se desarrollaron unas incipientes prácticas de archivo que fueron suficientes para la correcta administración de sus fondos documentales. Los encargados de la documentación supieron aunar la utilidad de sus trabajos con la practicidad de sus resultados. Su legado permitió que en los siglos siguientes se desarrollaran y perfeccionaran una serie de prácticas archivísticas que todavía hoy siguen siendo tributarias de los logros de aquellos anónimos oficiales señoriales.

\section{BIBLIOGRAFÍA CITADA}

Alfonso X, Las Siete Partidas, ed. José Sánchez-Arcilla Bernal, Madrid, Ed. Reus, 2004.

Beceiro Pita, Isabel (1998), El condado de Benavente en el siglo XV, Benavente, Centro de Estudios Benaventanos.

Beceiro Pita, Isabel; Córdoba de la Llave, Ricardo (1990), Parentesco, poder y mentalidad. La nobleza castellana, siglos XII-XV, Madrid, CSIC.

Calleja Puerta, Miguel (2002), Archivos dispersos, fuentes reencontradas. Notas metodológicas al estudio de las elites del reino de León en los siglos centrales de la Edad Media, "Medievalismo: Boletín de la Sociedad Española de Estudios Medievales" 12, pp. 9-36.

Calleja Puerta, Miguel (2014), Memoria escrita de la aristocracia en monasterios hispánicos de la edad románica, en García de Cortázar y Ruiz de Aguirre, José Ángel; Teja, Ramón (coords.), Monasterios y nobles en la España del románico: entre la devoción y la estrategia, Aguilar de Campoo, Fundación Santa María la Real - Centro de Estudios del Románico, pp. 207-229.

Castro, Américo (1921), Unos aranceles de aduana del siglo XIII, "Revista de Filología Española" 8, pp. 325-356.

Cavero Domínguez, Gregoria (2004), Los archivos nobiliarios y la edición y estudio de los derechos locales, "Revista de Historia Jerónimo Zurita" 78-79, pp. 69-84.

Chastang, Pierre (2001), Lire, écrire, transcrire. Le travail des rédacteurs de cartulaires en Bas-Languedoc (XI ${ }^{e}$-XIII ${ }^{e}$ siècles), París, CTHS.

Contel Barea, Concepción (1994), Fondos nobiliarios en el Archivo Histórico Nacional, "Cuadernos de Historia Moderna" 15, pp. 397-414.

Crespo Muñoz, Francisco Javier; Laguna Reche, Jesús Daniel; Fernández Valdivieso, José Luis; García Rodríguez, Marta Isabel; Martínez Guerra, 
María Inés; de la Peña Barroso, Efrén (2011), El Registro General del Sello durante el reinado de los Reyes Católicos: un acercamiento jurídico-administrativo y diplomático, en Cantarell Barella, Elena; Comas Via, Mireia (eds.), La escritura de la memoria: los Registros. VIII Jornadas de la Sociedad Española de Ciencias y Técnicas Historiográficas, Barcelona, Promociones y Publicaciones Universitarias, pp. 167-175.

Cuesta Nieto, José Antonio (2014), La Administración de la Casa de Velasco en el siglo XVII, "Historia, Instituciones, Documentos" 41, pp. 179-203.

Flores Varela, Carlos (1997), Sobre la organización de la documentación señorial: los casos del Marquesado de Villena, Condado de Montalbán y Ducado de Uceda, "Boletín de la ANABAD" 47/ 1, pp. 29-55.

García Ruipérez, Mariano; Fernández Hidalgo, María del Carmen (1999), Los Archivos Municipales en España durante el Antiguo Régimen. Regulación, conservación, organización y difusión, Cuenca, Universidad de Castilla-La Mancha.

Gil Adrados, Inmaculada; Gómez Vozmediano, Miguel Fernando (2009), Encuadernaciones artísticas en el Archivo de la Nobleza, Madrid, Ministerio de Cultura.

Gómez Vozmediano, Miguel Fernando (2001), El mundo de la cultura escrita y el universo de los Mendoza durante el Renacimiento castellano, en Casado Poyales, Antonio; Escudero Buendía, Francisco Javier; Llamazares Rodríguez, Fernando (coords.), Los Mendoza y el mundo renacentista. Actas de las I Jornadas Internacionales sobre Documentación Nobiliaria e Investigación en Archivos y Bibliotecas, Toledo, Asociación Profesional ANABAD - Cuenca, Editorial de la Universidad de Castilla La Mancha, pp. 91-105.

Gómez Vozmediano, Miguel Fernando (2007), Archivos nobiliarios españoles: pasado, presente y ifuturo? Tipología documental e investigación modernista, en Andújar Castillo, Francisco; Díaz López, Julián Pablo (coords.), Los señoríos en la Andalucía Moderna. El Marquesado de los Vélez, Almería, Instituto de Estudios Almerienses, pp. 129-210.

Gómez Vozmediano, Miguel Fernando (2012), La gestión patrimonial de la aristocracia castellana. Burocracia señorial, práctica contable y reflejo documental (siglos XV-XVIII), en Alloza Aparicio, Ángel; Fernández Izquierdo, Francisco; García Guerra, Elena (eds.), Comercio, banca y sociedad en los reinos hispánicos (siglos XIV-XVIII), Madrid, Ediciones Polifemo, pp. 227-277. 
Gómez Vozmediano, Miguel Fernando (en prensa), Los archivos nobiliarios como lugar de memoria de los linajes castellanos entre el Medievo y la Modernidad.

Lafuente Urién, Aránzazu (2010), Los archivos nobiliarios: formación y conservación. La Sección Nobleza del Archivo Histórico Nacional, en Sarasa, Esteban; Serrano, Eliseo (eds.), Estudios sobre señorío y feudalismo. Homenaje a Julio Valdeón, Zaragoza, Institución "Fernando el Católico", pp. 27-75.

Navarro Bonilla, Diego (2003), La imagen del archivo: representación y funciones en España (siglos XVI y XVII), Gijón, TREA.

Osorio Pérez, María José; de la Obra Sierra, Juan María; Moreno Trujillo, María Amparo (2007), Escribir y gobernar: el último registro de correspondencia del Conde de Tendilla (1513-1515), Granada, Universidad de Granada.

Pardo Rodríguez, María Luisa (1994-1995), La Diplomática señorial en la Corona de Castilla, "Estudis Castellonencs" 6, pp. 1018-1020.

Piera Miquel, Mónica (2012), Los muebles con secreto: esconder, exhibir, aprender, "Revista de Historia Moderna" 30, pp. 159-175.

Riquer, Martín de (ed.) (2003), Tesoro de la lengua castellana o española, Barcelona, Editorial Alta Fulla.

Rodríguez Bernis, Sofía (2006), Diccionario de Mobiliario, Madrid, Ministerio de Cultura, Secretaría General Técnica.

Romero Martínez, Adelina (1998), Los papeles del fisco. Estudio diplomático de la documentación fiscal castellana bajomedieval, Granada, Grupo Editorial Universitario.

Sánchez Mairena, Alfonso (2011), El impacto de la invasión musulmana en la construcción de la memoria institucional de la Iglesia lucense. El Alfa y el Omega del Tumbo Viejo de la catedral de Lugo (siglo XIII), en Prieto Entrialgo, Clara Elena (ed.), Arabes in patria Asturiensium, Oviedo, Universidad de Oviedo, pp. 75-101.

Sanz Fuentes, María Josefa (1999), Cancillerías señoriales, en La nobleza peninsular en la Edad Media, Ávila, Fundación Sánchez Albornoz, pp. 325-342.

Szmolka Clares, José; Moreno Trujillo, María Amparo; Osorio Pérez, María José (1996), Epistolario del conde de Tendilla, 1504-1506, Granada, Universidad de Granada.

Tacón Clavaín, Javier (2011), Soportes y técnicas documentales. Causas de su deterioro, Madrid, Ollero y Ramos.

Fecha de recepción del artículo: julio 2014

Fecha de aceptación y versión final: junio 2015 